Military Technical College Kobry Elkobbah, Cairo, Egypt.

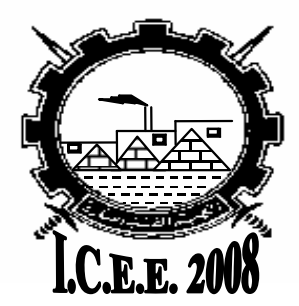

$4^{\text {th }}$ International Conference On

Chemical \& Environmental

Engineering

27-29 May 2008

\title{
METAL LOADED ZEOLITE CATALYSTS FOR THE DIRECT CONVERSION OF NATURAL GAS TO PETROCHEMICALS
}

\author{
Ahmed K. Aboul-Gheit ${ }^{a}$, Ahmed E. Awadallah ${ }^{a}$, Ahmed S. Youssef ${ }^{b}$, \\ El-Safai A. Gad ${ }^{a}$, Nagy E. Moustafa ${ }^{a}$, Mohammed S. El-Masry ${ }^{c}$
}

\begin{abstract}
The direct conversion of natural gas (methane) under non-oxidative condition to liquid fuels and chemicals of commercial importance is a process of prime importance. This process applies natural gas conversion to ethylene, benzene and little naphthalene via using fixed-bed flow reactor at $700^{\circ} \mathrm{C}$, gaseous hourly space velocity (GHSV) of $1500 \mathrm{ml} \mathrm{g}^{-1} \mathrm{~h}^{-1}$ and at time-on-stream up to $240 \mathrm{~min}$. This paper describes the data obtained using a catalysts prepared via impregnating the catalytic support (H-ZSM-5) with a molybdenum promoter (ammonium heptamolybdate) was compared with another catalyst prepared via mechanical mixing of Mo oxide powder with H-ZSM-5 zeolite. The data obtained reveal that the later catalyst is more active for benzene production throughout the whole time-on-stream range investigated. A $\mathrm{Mo} / \mathrm{SiO}_{2}$ (monfunctional) catalyst was tested and found of very low activity, substantiating the necessity of combining with a zeolitic support with the Mo component. Moreover, the unloaded H-ZSM-5 was tested and found also less active. Comparing replacing $\mathrm{H}-\mathrm{ZSM}-5$ with $\mathrm{H}-\mathrm{BEA}$ zeolite in the bifunctional catalyst shows the superiority of the former zeolite.
\end{abstract}

\section{KEY WORDS}

Natural gas; Methane; Dehydroaromatization; Molybdenum; H-ZSM-5; H-BEA.

\footnotetext{
Process Development Division, Egyptian Petroleum Research Institute, Nasr City, PO Box 9540, Cairo 11787, Egypt,

b Chemistry Department, Ain Shams University,

c Masr Oil Processing Co., Suez, Egypt
} 


\section{INTRODUCTION}

The direct catalytic conversion of methane into aromatics and hydrogen is an interesting route for upgrading natural gas [1-4]. It has been shown that supported molybdenum, preferentially Mo supported on H-ZSM-5, is active and selective for benzene formation from methane [5-8]. It has been established that at high temperatures, in presence of methane, molybdenum in $\mathrm{Mo} / \mathrm{H}-\mathrm{ZSM}-5$ is reduced and $\mathrm{Mo}_{2} \mathrm{C}$ species is formed [9]. During further activation of Mo/HZSM-5, the Mo species migrates towards exchangeable sites in the zeolite framework [9, 10]. It is generally reported that the activation of methane occurs on molybdenum active species forming ethylene as a primary product which converts to benzene over the protonic acid sites of the zeolite according to the following Scheme [5-10].

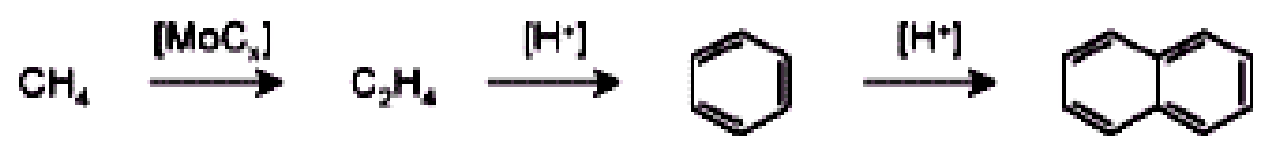

Over Mo/H-ZSM-5 zeolite [11-20], methane conversion and selectivities approach thermodynamic equilibrium for the conditions usually reported in the range 700 $800^{\circ} \mathrm{C}$ (methane conversion of $12 \%$ and selectivity for benzene and naphthalene higher than $90 \%$, at $700^{\circ} \mathrm{C}$ ).

Most researchers prepared the Mo/H-ZSM- 5 catalysts by impregnation of $\mathrm{H}-\mathrm{ZSM}-5$ using $\left(\mathrm{NH}_{4}\right)_{6} \mathrm{Mo}_{7} \mathrm{O}_{24}$ as a precursor of the $\mathrm{Mo}$ component. $\mathrm{Mo}_{7} \mathrm{O}_{24-6}$ phases may have located themselves on the external zeolite surface during the impregnation stage. On calcination at $500^{\circ} \mathrm{C}$, the Mo-containing ions decompose into $\mathrm{MoO}_{3}$ crystallites, and some of them migrate into the zeolite channels and interact with the Brønsted acid sites. Depending on the zeolite used and the preparation method, the optimum Mo loading for methane dehydroaromatization (MDA) ranges between 2 and 6\% [21]. It is reported $[22,23]$ that the Mo loading cannot be increased beyond $5-6 w t \%$ on samples prepared via impregnation of $\mathrm{H}-\mathrm{ZSM}-5$ with ammonium heptamolybdate. In case of high Mo loading or calcination at higher temperatures, the Mo species may extract the framework $\mathrm{Al}$ to form extra-framework $\mathrm{Al}$ first and then $\mathrm{Al}_{2}\left(\mathrm{MoO}_{4}\right)_{3}$ crystallites are formed, where the catalyst is deactivated.

\section{EXPERIMENTAL}

\subsection{Preparation of H-ZSM-5 Zeolite}

The Na-ZSM-5 zeolite (Süd Chemie AG, Germany) is calcined in air at $500^{\circ} \mathrm{C}$ for $3 \mathrm{~h}$ to remove any templating agent that may be remaining after zeolite synthesis. The Na-ZSM-5 was transformed to the corresponding $\mathrm{NH}_{4}-\mathrm{ZSM}-5$ via exchanging with a molar solution of $\mathrm{NH}_{4} \mathrm{NO}_{3}$ under reflux at $70^{\circ} \mathrm{C}$ several times, each for $8 \mathrm{~h}$ using fresh solutions. The $\mathrm{NH}_{4}$-form produced was then separated, washed several times with distilled water to remove $\mathrm{NO}_{3}$ ions, dried at $110^{\circ} \mathrm{C}$ overnight then calcined in air at $500^{\circ} \mathrm{C}$ for $3 \mathrm{~h}$ to convert them to $(\mathrm{H}-\mathrm{ZSM}-5)$. 


\subsection{Preparation of the Impregnated Catalysts}

A monometallic catalyst containing $6.0 \mathrm{wt} \%$ Mo supported on $\mathrm{H}-\mathrm{ZSM}-5$ was prepared by incipient wetness impregnation of $\mathrm{H}-\mathrm{ZSM}-5$ with an aqueous solution of ammonium heptamolybdate to which citric acid was added to improve the penetration of the metal into the zeolite pores [24, 25]. These preparations were dried at $110^{\circ} \mathrm{C}$ overnight, then, calcined in air at $530^{\circ} \mathrm{C}$ for $4 \mathrm{~h}$ to obtain $6.0 \mathrm{wt} \% \mathrm{Mo} / \mathrm{H}-\mathrm{ZSM}-5$ catalyst. Similarly, $6.0 \mathrm{wt} \% \mathrm{Mo} / \mathrm{SiO}_{2}$ catalyst was prepared.

\subsection{Preparation of Mechanically Mixed Catalysts}

The metal oxide powder $\left(\mathrm{MoO}_{3}\right)$ was obtained by calcining ammonium heptamolybdate in air at $550^{\circ} \mathrm{C}$ for $4 \mathrm{~h}$, then mechanically mixed with $\mathrm{H}-\mathrm{ZSM}-5$ zeolite powder to produce different contents of monometallic Mo oxides ranging from 06.0wt\%Mo up to $18.0 w t \% M o$ supported on $\mathrm{H}-\mathrm{ZSM}-5$.

\subsection{Catalytic Reactor and Analysis}

Natural gas conversion was carried out under atmospheric pressure using a downflow fixed bed reactor composed of a silica tube $1.5 \mathrm{~mm}$ ID charged with $0.5 \mathrm{~g}$ catalyst heated at $700^{\circ} \mathrm{C}$ and a gas hourly space velocity (GHSV) of $1500 \mathrm{ml} \mathrm{g}^{-1} \mathrm{~h}^{-1}$ at a time-on-stream of $240 \mathrm{~min}$. The hydrocarbon product was analyzed by Arnel Perkin Elmer-Claurs 500 Natural gas analyzer.

\subsection{Catalyst Characterization}

\subsubsection{X-Ray diffraction patterns of the catalysts (XRD)}

The X-ray diffraction patterns of the unloaded zeolite catalysts under study were carried out using a Phillips X Pert Diffractometer PW 1390 at $40 \mathrm{kV}$ and30 mA with Ni filter and $\mathrm{Cu}$ Ka radiation. The XRD runs were carried out up to $2 \theta$ of $50^{\circ}$.

\subsubsection{Thermal gravity analysis (TGA)}

Coke deposited on different Mo/H-ZSM-5 catalysts was analyzed by thermogravimetric analysis (TGA) using Shimadzu TGA-50H apparatus.

\section{RESULTS AND DISCUSSION}

\subsection{Catalytic Conversion of Natural Gas to Benzene}

\subsubsection{Using molybdenum oxide/H-ZSM-5 catalysts}

In general, the discovery of crude oil reservoirs is diminishing allover the world, whereas the natural gas reservoirs are increasing. The conversion of natural gas to petrochemicals is a research trend of prime importance. In this work, a direct catalytic conversion of $\mathrm{CH}_{4}$ (the principal natural gas component) to olefins and aromatics is to be heterogeneously carried out using catalysts containing molybdenum oxide supported on a solid porous material. In this work, we have considered the diffusion effect in a fixed-bed, heterogeneously catalyzed process since the reacting molecules are much 
smaller than the produced molecules. The published work on this type of reactions used H-ZSM-5 zeolite as a support for the catalytic metal oxide [26, 27].

Traditionally, the metallic catalytic phase is impregnated in the solid support and used as a catalyst charged in a fixed-bed reactor heated at $700^{\circ} \mathrm{C}$, however, the reaction may reveal that the produced aromatic molecules should encounter significant diffusion limitation caused by molecular size enlargement. Hence, catalysts containing mechanically mixed $\mathrm{MoO}$ and $\mathrm{H}-\mathrm{ZSM}-5$ zeolite powders are expected to reduce or even exclude both interparticle and intraparticle diffusion restrictions. Therefore, we have correlated the reaction of natural gas over mechanically mixed powders of $6.0 \mathrm{wt} \% \mathrm{MoO}$ plus $94.0 \mathrm{wt} \%$ of $\mathrm{H}-\mathrm{ZSM}-5$ in a fixed-bed reactor at the same reaction conditions over another catalyst containing $6.0 \mathrm{wt} \% \mathrm{Mo} / \mathrm{H}-\mathrm{ZSM}-5$ prepared via wet impregnation method. Even though, the overall X-ray diffraction patterns (Fig. 1) obtained using these two $6 \% \mathrm{Mo} / \mathrm{H}-\mathrm{ZSM}-5$ catalysts (prepared by mechanical mixing or by impregnation) are found to be very similar between $2 \theta$ of 5 to $30^{\circ}$, indicating indifferent crystallinities of the zeolitic components in spite of the large difference of the overall catalysts. This can also be indicative that the actual contact (proximity) between the metallic and acid sites is almost indifferent. As a matter of fact, all of the diffraction peaks appearing in Fig. 1 for the $6 \% \mathrm{Mo} / \mathrm{H}-$ ZSM- 5 catalysts are principally attributed to the zeolite.

The data in Fig. 3 show that the catalyst composed of mechanically mixed 6.0 wt $\% \mathrm{MoO}$ with $\mathrm{H}-\mathrm{ZSM}-5$ zeolite is more active than the impregnated catalyst version at all time-on-stream values up to $240 \mathrm{~min}$. Evidently, mechanical mixing of the metallic and H-ZSM-5 phases realizes the exclusion of significant diffusion restriction through producing a rather voluminous aromatic molecule compared to the starting methane molecule. Fig. 3 also shows that during the first hour of time-onstream, the difference in benzene production is much smaller than that produced during longer time-on-stream (120-240 min). For real application, the diffusion factor has thus to be taken into consideration in designing the catalytic reactor regarding acquiring the optimum stabilization of mixed powders used in long time-on-stream conditions. Nevertheless, Chen et al. [28] have compared a physically mixed of $16 \mathrm{wt} \% \mathrm{MoO}_{3}$ powder with $\mathrm{H}-\mathrm{ZSM}-5$ powder vs. a lower metal containing catalyst $\left(6 \mathrm{wt} \% \mathrm{MoO}_{3} / \mathrm{H}-\mathrm{ZSM}-5\right)$ prepared using the impregnation method and found that the former catalyst exhibits a better performance for methane conversion. They attributed this difference to the larger specific surface area of the physically mixed catalyst and also believed that both hcp $\beta-\mathrm{Mo}_{2} \mathrm{C}$ and fcc $\alpha-\mathrm{Mo}_{2} \mathrm{C}$ are formed on the physically mixed samples, while only hcp $\beta-\mathrm{Mo}_{2} \mathrm{C}$ is formed on the impregnated samples under the same reaction condition.

However, during the XRD range of $2 \theta$ between 30 and $50^{\circ}$, we show the magnified small bands appearing (Fig. 2) that exhibit some important details. For the two catalysts containing $6 \% \mathrm{Mo} / \mathrm{H}-\mathrm{ZSM}-5$, either prepared by impregnation or mechanical mixing there appear two diffraction bands at $2 \theta=37.3$ and $39.5^{\circ}$ which are assumed to belong to $\beta$-Mo carbide. However, at $2 \theta$ of 36.5 and $42^{\circ}$ in only the XRD of the catalyst prepared by mechanical mixing two bands appear. These bands don't appear in the diffraction pattern of the impregnated catalyst. These bands are attributed to a-Mo carbide deposited on this mechanically mixed catalyst. Derouane and coworkers $[14,29]$ have shown that the $\alpha$-Mo carbide is more active for the 
formation of ethylene than the $\beta$-Mo carbide. Hence, it can be assumed that not only the exclusion or even decrease of diffusion restriction has activated the mechanically mixed catalyst, but also the formation of $\alpha$-Mo carbide has added a contribution.

The selectivity curves (Figs 4 and 5) show higher formation of benzene associated with a corresponding lower formation of naphthalene on the impregnated catalyst. This may be attributed to the intimate contact of acid sites with metallic sites in this catalyst. This assumption may be substantiated by the accelerated naphthalene formation at the initial stage at $5 \mathrm{~min}$ where $61 \%$ selectivity of naphthalene occurs while $30 \%$ selectivity of benzene occurs (Fig. 4) indicating that "clean" surface of the impregnated catalyst contain closely connected acid and metallic sites. Beyond $5 \mathrm{~min}$, the benzene selectivity jumps to around $75 \%$ whereas that of naphthalene drops to $20 \%$ during a time-on-stream up to $240 \mathrm{~min}$. However, the selectivities of these products on the mechanically mixed catalyst are not exhibiting variation.

Coke formation at the initial time-on-stream $(5 \mathrm{~min})$ is $12 \%$ on the mechanically mixed catalyst, whereas it is as high as $32.5 \%$ on the impregnated catalyst (Fig. 6). Although these values drop beyond $5 \mathrm{~min}$ to comprise 0.5 and $1.1 \%$ at $30 \mathrm{~min}$, respectively, the impregnated catalyst remains to be a higher producer of coke compared to the mechanically mixed one at all time-on-stream values up to $240 \mathrm{~min}$. This excessive coke formation on the impregnated catalyst can be considered a third contributor to the lower activity of this catalyst for producing ethylene and consequently benzene, compared to that on the mechanically mixed catalyst.

To examine the role of H-ZSM-5 zeolite as an important partner in the catalytic activity, the active metallic phase $(6.0 \mathrm{wt} \% \mathrm{MoO})$ has been supported on $\mathrm{SiO}_{2}$ granules, which acquire a large surface area, almost equals to that of the H-ZSM-5 zeolite under study $\left(500 \mathrm{~m}^{2} / \mathrm{g}\right)$, but does not acquire any strong acid sites. Fig. 3 again shows that this $\mathrm{MoO} / \mathrm{SiO}_{2}$ catalyst acquires almost $1 / 8$ the activity of the MoO/H-ZSM-5 catalyst for benzene production from natural gas. Table 1 shows that the $6 \% \mathrm{Mo} / \mathrm{SiO}_{2}$ catalyst (No. 2) is the only catalyst that does not produce naphthalene, which may add an evidence that the aromatization activity is greatly dependent on the strong acid sites of the zeolite component. Moreover, the lowest aromatics production observed among all experiments using the catalysts in Table 1, i.e., $0.39 \mathrm{wt} \%$, has been obtained using the $\mathrm{Mo} / \mathrm{SiO}_{2}$ catalyst, whereas on the unloaded $\mathrm{H}-\mathrm{ZSM}-5$, aromatics comprise $0.97 \mathrm{wt} \%$.

On the other hand, the unloaded H-ZSM-5 zeolite alone (Fig. 1) has been examined to catalyze benzene production from methane under the same conditions, but also found to acquire low activity $(\sim 1 / 5$ that of MoO/H-ZSM-5). The sum of the activities of the $6.0 \mathrm{wt} \% \mathrm{Mo} / \mathrm{SiO}_{2}$ catalyst plus the activity of $\mathrm{H}-\mathrm{ZSM}-5$ zeolite (Fig. 1) equals 0.325 of the activity of the $6.0 \mathrm{wt} \% \mathrm{Mo} / \mathrm{H}-\mathrm{ZSM}-5$ catalyst. This proves the necessity of catalytic bifunctionality (i.e.; metal sites combined with acid sites) for this reaction. However, with respect to how the reaction proceeds, first Wang et al. $[9,30]$ observed that $\mathrm{CH}_{4}$ reduces the $\mathrm{Mo}^{+6}$ to $\mathrm{Mo}_{2} \mathrm{C}$ during the initial induction period and believed that molybdenum carbide (or oxycarbide) is responsible for transforming $\mathrm{CH}_{4}$ to $\mathrm{C}_{2} \mathrm{H}_{4}$ which again transforms to a benzenoid structure over the acidic sites in the zeolitic channels. However, the molybdenum loading in catalysts prepared by impregnation of the H-ZSM-5 zeolite with ammonium heptamolybdate can not be 
more than $6 \%$ wt because on calcinations higher Mo species can extract $\mathrm{Al}$ from the zeolite framework forming $\mathrm{Al}_{2}\left(\mathrm{MoO}_{4}\right)_{3}$ that deactivates the catalyst $[22,23]$.

The loading of MoO, mechanically mixed with $\mathrm{H}-\mathrm{ZSM}-5$ support in various proportions has been investigated between 6.0 and $18.0 \mathrm{wt} \%$ (Fig. 7). It is found that the $6.0 \mathrm{wt} \% \mathrm{MoO} / \mathrm{H}-\mathrm{ZSM}-5$ catalyst acquires the highest activity, whereas the $18 \mathrm{wt} \% \mathrm{MoO}$ containing catalyst is the least active. This systematic decrease of the catalytic activity for methane conversion to aromatics with the increase of the metallic component is ascribed to: a) attaining higher diffusion restriction along the pores of the zeolite and b) the larger percentage of $\mathrm{MoO}$ has masked or at least overbalanced the acid sites in the zeolite component of the catalyst. These acid sites are principally included in the system of channels in the zeolite and their overloading with MoO should increase the diffusion resistance of the benzene molecules produced and hence their production decreases.

Fig. 8 compares the activities of a catalyst composed of H-ZSM-5 zeolite loaded with $6 \%$ Mo catalysts with H-BEA zeolite loaded with the same metal phase component. In both mechanically mixed and impregnated forms, the H-ZSM- 5 supported catalyst is several times superior over the H-BEA supported catalyst, although the acidic properties of both zeolites are not significantly different and both zeolites acquire tridirectional pore systems. The main difference between the two zeolites is the channel dimension; in H-ZSM-5 it is $\sim 6.0 \AA$ whereas in H-BEA zeolite it is $\sim 10 \AA$.

\subsection{Catalytic Conversion of Natural Gas to Olefins}

The production of olefinic molecules during natural gas conversion at a temperature of $700^{\circ} \mathrm{C}$ principally amounts to at least $90 \%$ of ethylene with propylene as the remaining product. The conversion of natural gas (methane) to olefins as a function of time-on-stream using two $6.0 \mathrm{wt} \% \mathrm{Mo} / \mathrm{H}-\mathrm{ZSM}-5$ catalysts; one prepared via mechanical mixing of $\mathrm{MoO} / \mathrm{H}-\mathrm{ZSM}-5$ zeolite and another prepared via impregnation of ammonium heptamolybdate solution in H-ZSM-5 zeolite, is depicted in Fig. 9. Similar to our findings using these catalysts for benzene production (Fig. 1), the yield of olefins also is higher on the mechanically mixed catalyst than on the impregnated one.

Nevertheless, Fig. 9 shows that the mono-functional catalysts $6.0 \mathrm{wt} \% \mathrm{Mo} / \mathrm{SiO}_{2}$ (catalyst No. 2) and the unloaded H-ZSM-5 (catalyst No. 1) which possess either a metallic component or an acidic component, respectively exhibit relatively higher catalytic activities for production of olefins than the bi-functional catalysts, e.g., the $6.0 \mathrm{wt} \% \mathrm{Mo} / \mathrm{H}-\mathrm{ZSM}-5$ catalysts at all times-on-stream investigated. Mostly, the activity of the activity of themonofunctional $\mathrm{Mo} / \mathrm{SiO}_{2}$ catalyst is almost twice more active than the monofunctional H-ZSM-5 catalyst, i.e., the metal component is more significantly active for catalyzing the formation of two doubly bonded carbon atoms (ethylene) via combining two single carbons from two methane molecules together. The absence of strong acid sites in the $\mathrm{Mo} / \mathrm{SiO}_{2}$ catalyst does not allow the ethylene molecules formed to be cyclized and producing benzene, and hence, ethylene accumulates. Therefore, if the conversion of methane is to be directed to ethylene production, the metallic component supported on a non-acidic high surface area solid can be used 
as a catalyst. During calcination of the $\mathrm{Mo} / \mathrm{SiO}_{2}$ catalyst before carrying out the natural gas conversion, $\mathrm{Mo}$ in the precursor is oxidized to $\mathrm{MoO}_{3}$ which is then carbided to $\mathrm{Mo}_{2} \mathrm{C}$. This carbide is assumed $[30,31]$ to be the active phase that contributes to catalyzing the cyclization of ethylene. Fig. 9 also shows that the strong acid sites present in the channels of H-ZSM-5 zeolite are also capable of forming ethylene through reacting two adsorbed methane molecules. The evident decrease of olefins as a function of time-on-stream can be attributed to the continuous carbon deposition in the zeolite channels.

Fig. 10 shows that the reaction of olefins production from natural gas using three catalysts containing $6.0,12.0$ and $18.0 \mathrm{wt} \%$ Mo on H-ZSM-5 (catalysts 4,5 and 6 , respectively, Table 1) behaves generally in contra-wise trend relative to producing aromatics (benzene) (Fig. 4). Benzene decreases as the metal loading increases, whereas the light olefins product (mainly ethylene) increases with metal loading, particularly, at larger time-on-stream (beyond $120 \mathrm{~min}$ ). This finding also proves that intimate accessibility to both metallic sites and the zeolitic acid sites occurs where still natural gas molecules persist on the highly loaded mechanically mixed preparations. Moreover, it can be assumed that at time-on-stream higher than $100 \mathrm{~min}$, there is insignificant diffusion restriction encountered by the high metallic component loadings since the olefinic product molecules (ethylene and little propylene) are of very small size compared to the aromatic molecules.

\section{CONCLUSION}

Molybdenum (Mo) and H-ZSM-5 zeolite are the principal components in catalyzing the production of olefins and aromatics from natural gas. A higher Mo content above $>6.0 \mathrm{wt} \%$ in a catalysts containing H-ZSM-5 causes a decrease of aromatics formation, but an increase of olefins (ethylene) formation. Diffusion, principally intraparticle diffusion, plays a significant role in inhibiting aromatics formation on the impregnated Mo/H-ZSM-5 catalysts, compared to those prepared by mechanical mixing the $\mathrm{MoO}_{3}$ and $\mathrm{H}-\mathrm{ZSM}-5$ zeolite. First $\mathrm{MoO}_{3}$ transforms to $\mathrm{Mo}_{2} \mathrm{C}$ which activates the formation of olefins (mainly ethylene) from natural gas (methane) then these olefins transform to aromatics by reaction on the strong acid sites of the zeolite.

\section{REFERENCES}

[1] Lunsford, J.H., Catal. Today, 63, 165 (2000).

[2] Tang, S., Chen, Lin, H. J., Tan, K.L., Catal. Commun., 2, 31 (2001).

[3] Xu, Y., Bao, X., Lin, L., J. Catal. 216, 386 (2003).

[4] Sarioglan, A., Erdem-Senatalar, A., Savasci, O.T., Taarit, Y.B. J. Catal., 226, 210 (2004).

[5] Xu, Y., Liu, S., Wang, L., Xie, M., Guo, X., Catal. Lett., 30, 135 (1995).

[6] Solymosi, F., Erdölelyi, A., Azöbe, A., Catal. Lett., 32, 43 (1995).

[7] Shu, Y., Xu, Y., Wong, S.T., Wang, L., Guo, X., J. Catal., 170, 11 (1997).

[8] Lunsford, J.H., Rosynek, M.P., Wang, D., Stud. Surf. Sci. Catal., 107, 257 (1997). 
[9] Wang, D., Lunsford, J.H., Rosynek, M.P., J. Catal., 169, 347 (1997).

[10] Borry III, R.W., Lu, E.C., Ho Kim, Y., Iglesia, E., Stud. Surf. Sci. Catal., 119, 403 (1998).

[11] Wang, L., Huang, J., Tao, L., Xu, Y., Xie, M., Xu, G., Catal. Lett., 21, 35 (1993).

[12] Liu, S., Wang, L., Ohnishi, R., Ichikawa, M., J. Catal., 181, 175 (1999).

[13] Rival, O., Grandjean, B.P.A., Guy, C., Sayari, A., Larachi, F., Ind. Eng. Chem. Res., 40, 2212 (2001).

[14] Bouchy, C., Schmidt, I., Anderson, J.R., Jacobsen, C.J.H., Derouane, E.G., Derouane-Abd Hamid, S.B., J. Mol. Catal., A 163, 283 (2000).

[15] Weckhuysen, B.M., Rosynek, M.P., Lunsford, J.H., Catal. Lett., 52, 31 (1998).

[16] Weckhuysen, B.M., Wang, D., Rosynek, M.P., Lunsford, J.H., J. Catal., 175, 338 (1998).

[17] Weckhuysen, B.M., Wang, D., Rosynek, M.P., Lunsford, J.H., J. Catal., 175, 347 (1998).

[18] Li, W., Meitzner, G.D., Borry III, R., Iglesia, E., J. Catal., 191, 373 (2000).

[19] Ding, W., Meitzner, G.D., Iglesia, E., J. Catal., 206, 14 (2002).

[20] Dong, X., Song, Y., Lin, W., Catal. Commun., 8, 539 (2007).

[21] Ma, D., Zhang, W., Shu, Y., Xu, Y., Bao, X., Catal. Lett., 66, 155 (2000).

[22] Xu, Y., Liu, W., Wong, S., Guo, X., Catal. Lett., 40, 207 (1996).

[23] Kim, Y., Borry III, R.W., Iglesia, E., Microporous Mesoporous Mater., 35-36, 495 (1997).

[24] Aboul-Gheit, A.K, J. Chem. Technol. Biotechnol., 29, 480 (1979).

[25] Aboul-Gheit, A.K, Abdel-Hamid, S.M., In G. Poncelet, Martens, B. Delmon, P. A. Jacobs, P. Grange (Eds.), Scientific Bases for the Preparation of Heterogeneous Catalysts VI, Stud.Surf. Sci. Catal., vol. 91, Elsevier, Amesterdam, 1995, p. 1131.

[26] Xu, Y., Lin, L., Appl. Catal. A: Gen., 188, 53 (1999).

[27] Xu, Y., Bao, X., Lin, L., J. Catal., 216, 386 (2003).

[28] Chen, L., Lin, J., Zeng, H.C., Tan, K.L., Catal. Commun., 2, 201 (2001).

[29] Hamid, S.B.D., Anderson, J.R., Schmidt, I., Bouchy, C., Jacobsen, C.J.H., Derouane, E.G., Catal. Today, 63, 461 (2000).

[30] Wang, D., Lunsford, J.H., Rosynek, M.P., Topic Catal., 3, 289 (1996).

[31] Wang, D., Lunsford, J.H., Rosynek, M.P., J. Catal., 169, 289 (1997). 
Table 1. Natural gas conversion to olefins and aromatics as well as selectivity of aromatic products using the catalysts under study.

Reaction temperature $=700^{\circ} \mathrm{C}, \mathrm{CHSV}=1500 \mathrm{ml} / \mathrm{g} / \mathrm{h}$ and Time-on-stream $=60 \mathrm{~min}$, $\mathrm{C}_{2}+$ means ethylene and propylene

\begin{tabular}{|c|c|c|c|c|c|c|c|}
\hline \multicolumn{2}{|r|}{ Catalyst } & \multirow{2}{*}{$\begin{array}{c}\text { Natural Gas } \\
\text { (Methane) } \\
\text { Conversion (wt\%) }\end{array}$} & \multicolumn{3}{|c|}{ Selectivity (\%) } & \multicolumn{2}{|c|}{ Yield (wt\%) } \\
\hline & Name & & $\mathrm{C}_{6} \mathrm{H}_{6}$ & $\mathrm{C}_{7} \mathrm{H}_{8}$ & $\mathrm{C}_{10} \mathrm{H}_{8}$ & $\mathrm{C}_{2}+$ & Aromatics \\
\hline (1) & H-ZSM-5 & 3.1 & 70.1 & 6.19 & 23.71 & 2.13 & 0.97 \\
\hline (2) & $6 \%{\mathrm{Mo} / \mathrm{SiO}_{2}}$ & 4.59 & 92.31 & 7.96 & 0.0 & 4.56 & 0.39 \\
\hline (3) & 6\%Mo(imp)/H-ZSM-5 & 5.97 & 73.78 & 5.24 & 20.98 & 0.25 & 5.72 \\
\hline (4) & $6 \% \mathrm{Mo}(\mathrm{m}) / \mathrm{H}-\mathrm{ZSM}-5$ & 6.37 & 71.41 & 6.79 & 21.81 & 0.18 & 6.19 \\
\hline (5) & $12 \% \mathrm{Mo}(\mathrm{m}) / \mathrm{H}-\mathrm{ZSM}-5$ & 4.74 & 69.25 & 3.52 & 27.23 & 0.48 & 4.26 \\
\hline (6) & $18 \% \mathrm{Mo}(\mathrm{m}) / \mathrm{H}-\mathrm{ZSM}-5$ & 3.07 & 80.07 & 6.87 & 13.06 & 0.16 & 2.91 \\
\hline (7) & 6\%Mo(imp)/H-BEA & 4.22 & 72.63 & 1.12 & 26.26 & 2.43 & 1.79 \\
\hline (8) & $6 \% \mathrm{Mo}(\mathrm{m}) / \mathrm{H}-\mathrm{BEA}$ & 2.65 & 74.26 & 1.03 & 24.1 & 0.7 & 1.95 \\
\hline
\end{tabular}




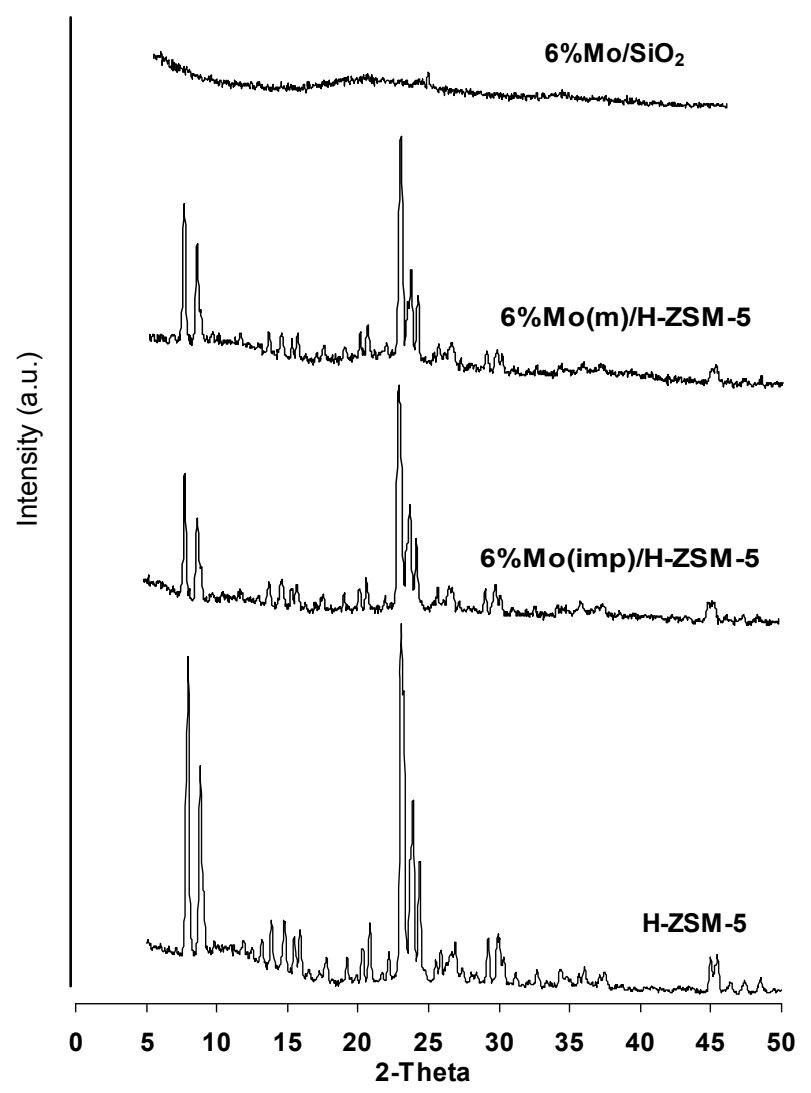

Fig. 1. XRD patterns of unloaded H-ZSM-5 and $6 \mathrm{wt} \%$ Mo supported on H-ZSM-5 either by impregnation or mechanical mixing after 

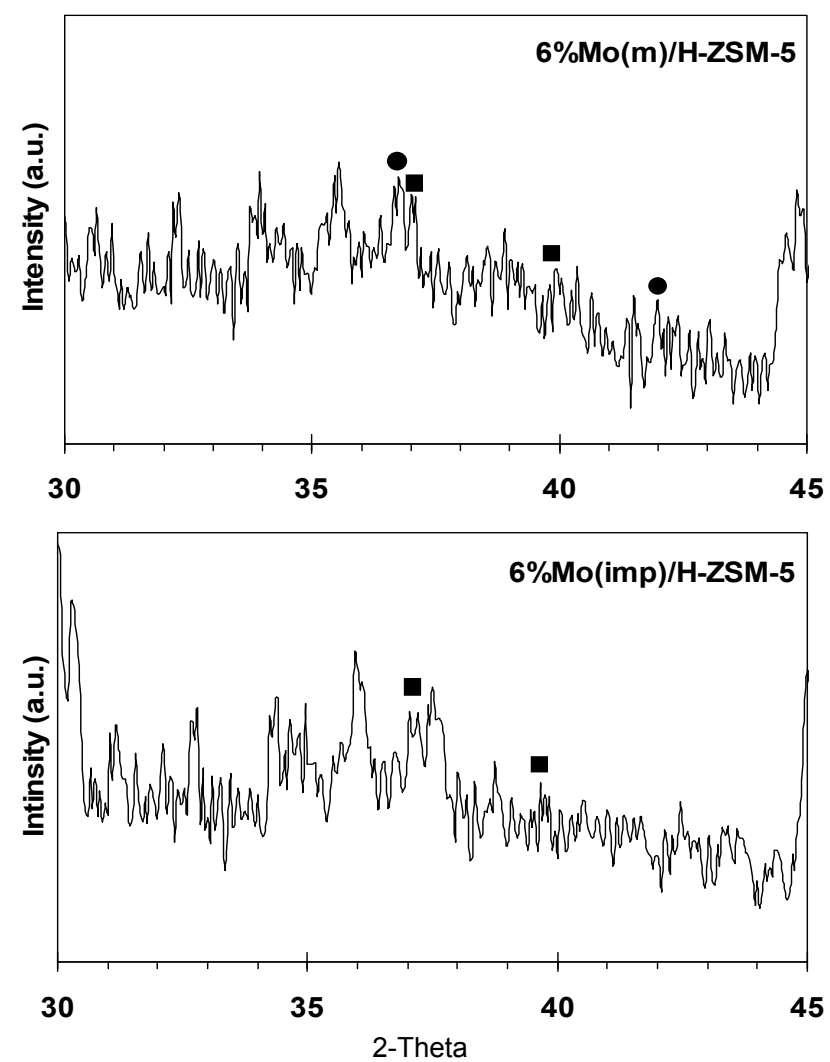

Fig. 2. XRD Patterns of $6 \% \mathrm{Mo}(\mathrm{imp}) / \mathrm{H}-\mathrm{ZSM}-5$ and $6 \% \mathrm{Mo}(\mathrm{m}) / \mathrm{H}-\mathrm{ZSM}-5$ after reaction, $(\bullet)$ a-MoC and (匹) $\beta$-MoC Phases.

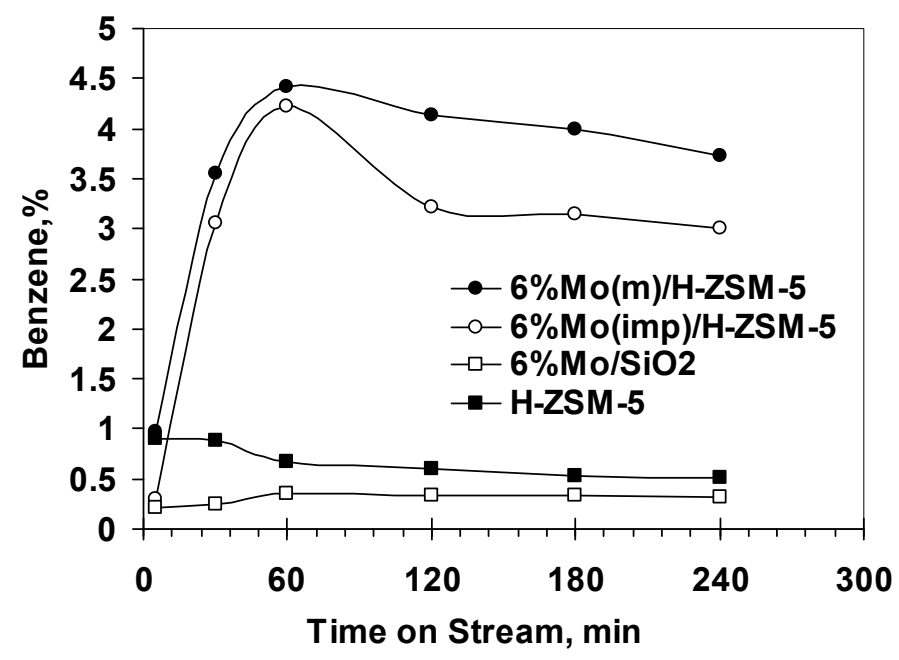

FIG. 3. Benzene formation as a function of time on stream using unloaded $\mathrm{H}-\mathrm{ZSM}-5$ and impregnated and mechanical Mo supported on H-ZSM-5 or $\mathrm{SiO}_{2}$ catalysts. 


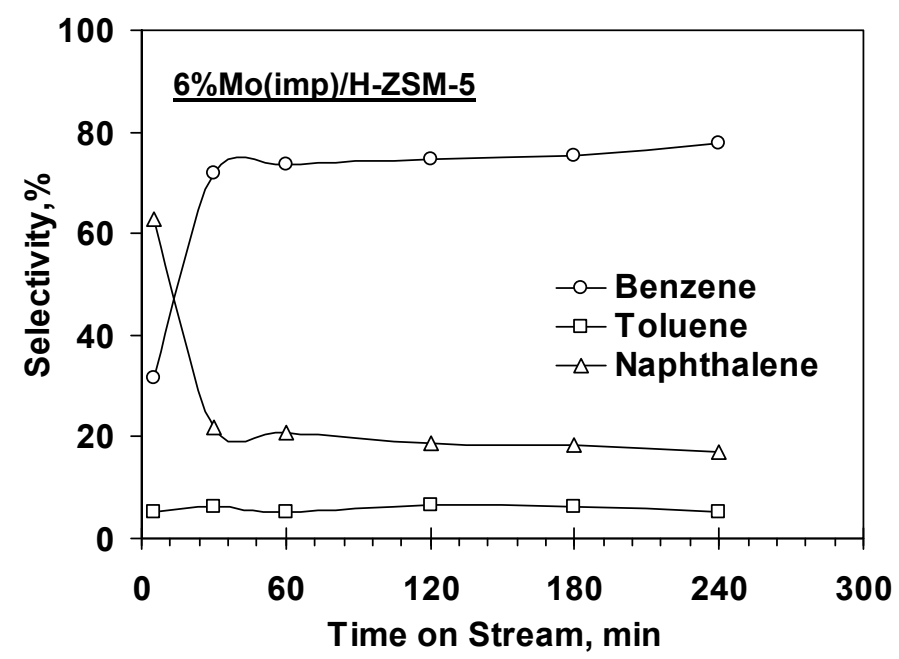

Fig. 4. Selectivity of aromatic products as a function of time on stream using $6 \% \mathrm{Mo}(\mathrm{imp}) / \mathrm{H}-\mathrm{ZSM}-5$ catalyst.

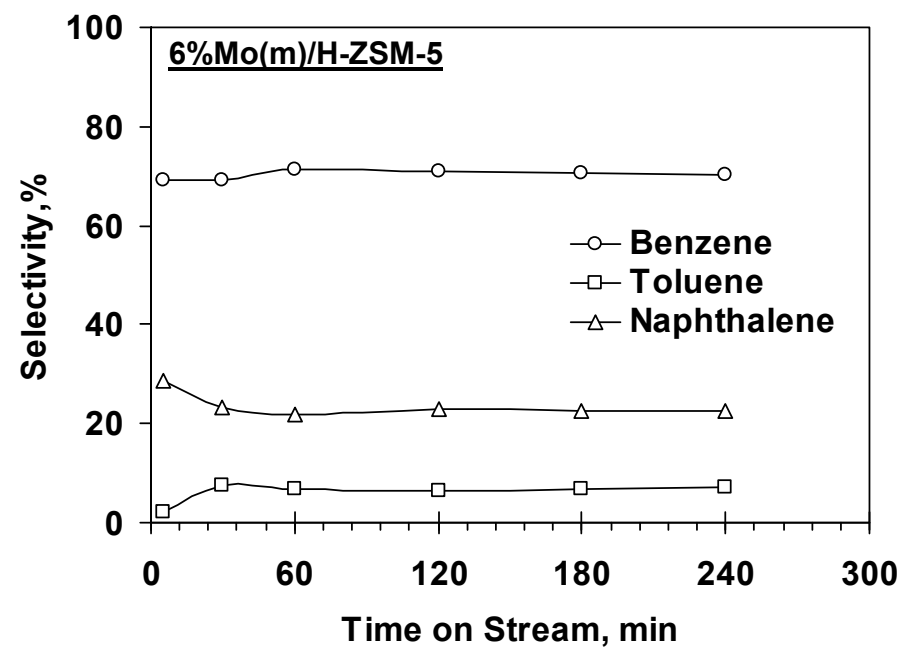

Fig. 5. Selectivity of aromatic products as a function of time on stream using $6 \% \mathrm{Mo}(\mathrm{m}) / \mathrm{H}-\mathrm{ZSM}-5$ catalyst.

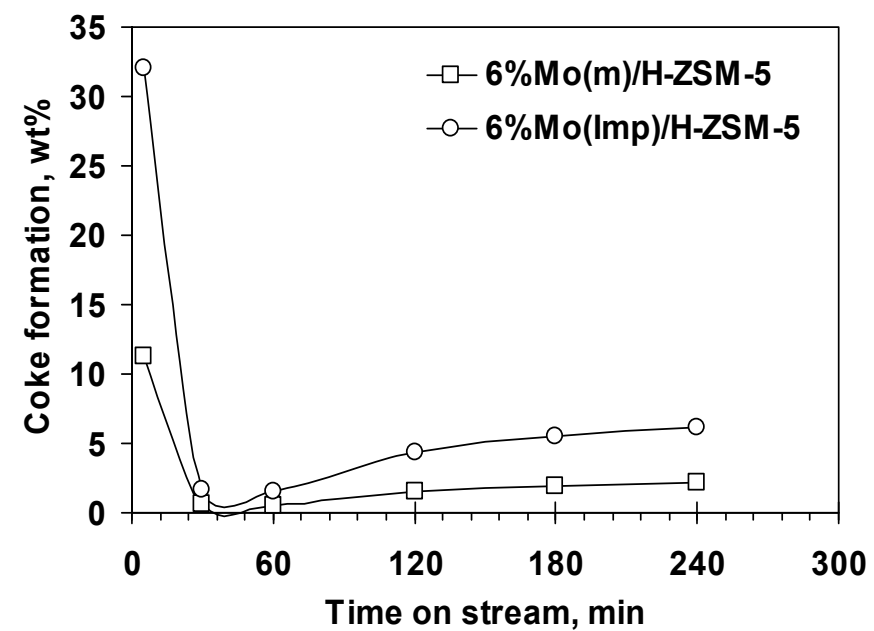

Fig. 6. Coke formation as a function of time on stream using impregnated and mechanical Mo supported on H-ZSM- 5 catalysts. 


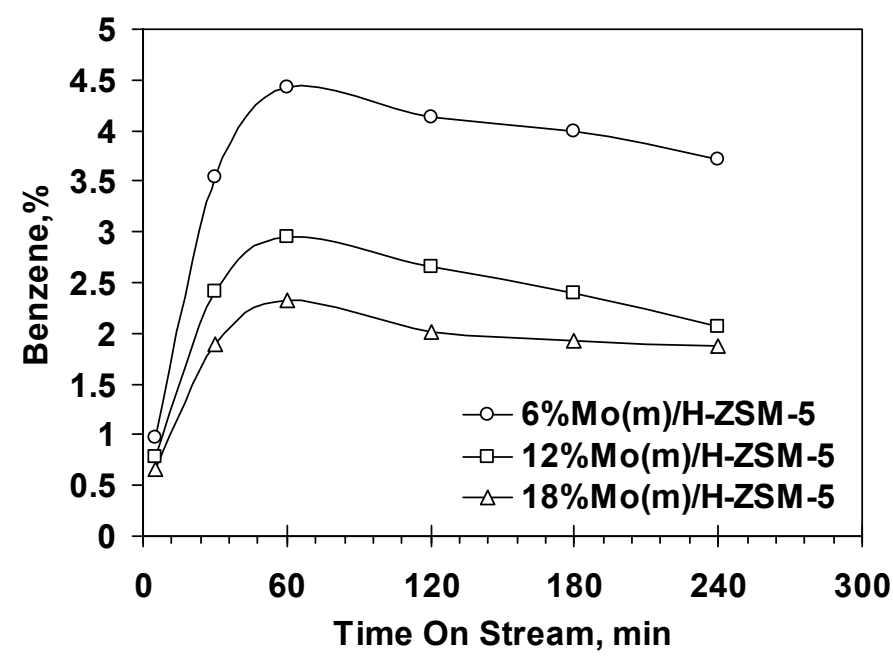

Fig. 7. Benzene formation as a function of time on stream using mechanical Mo supported on H-ZSM-5 catalysts with different Mo loadings.

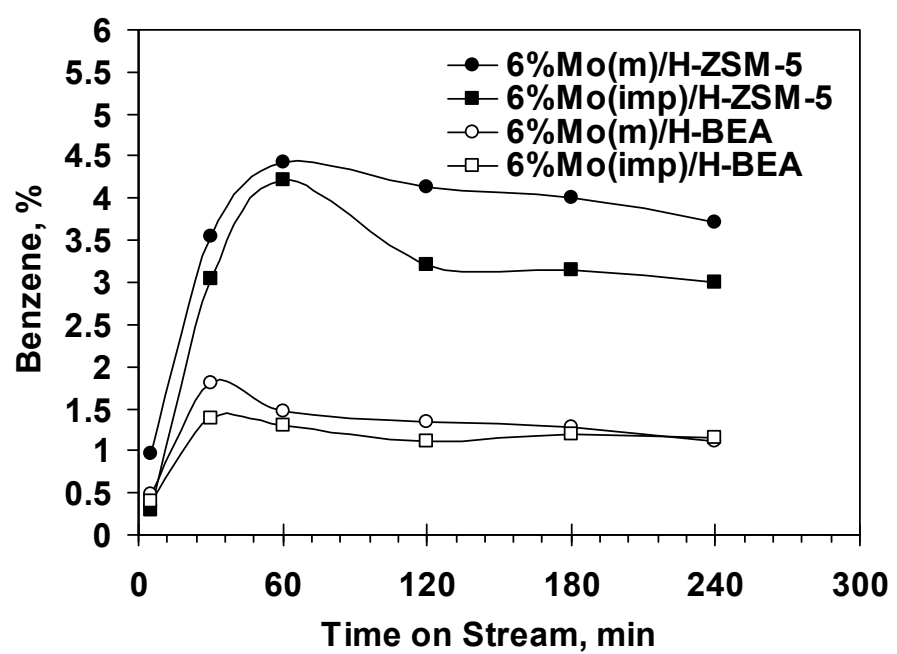

Fig. 8. Benzene formation as a function of time on stream using impregnated and mechanical Mo supported on H-ZSM-5 and H-BEA catalysts. 


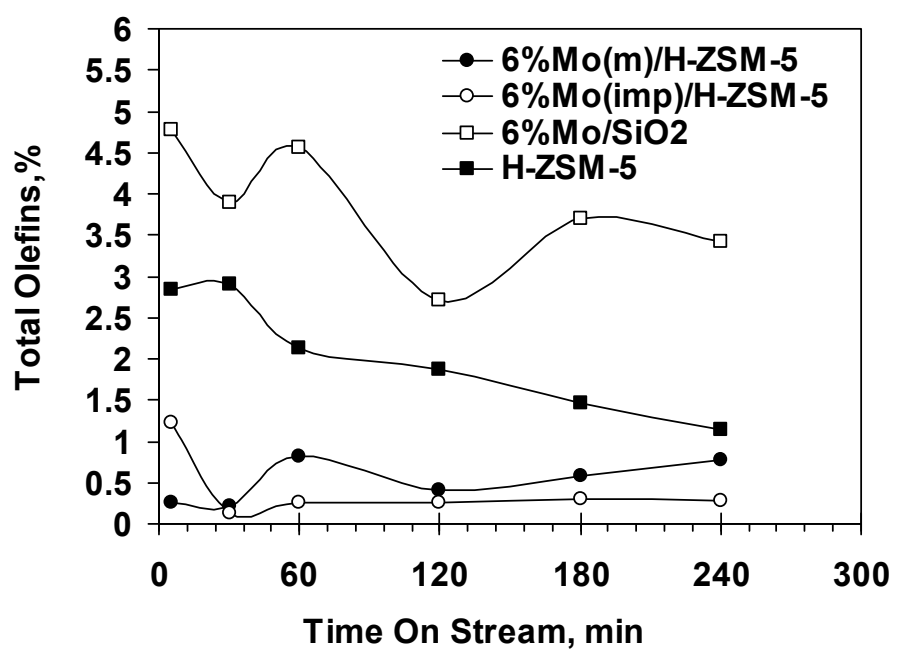

Fig. 9. Total olefins as a function of time on stream using impregnated and mechanical Mo supported on $\mathrm{H}-\mathrm{ZSM}-5$ or $\mathrm{SiO}_{2}$ catalysts.

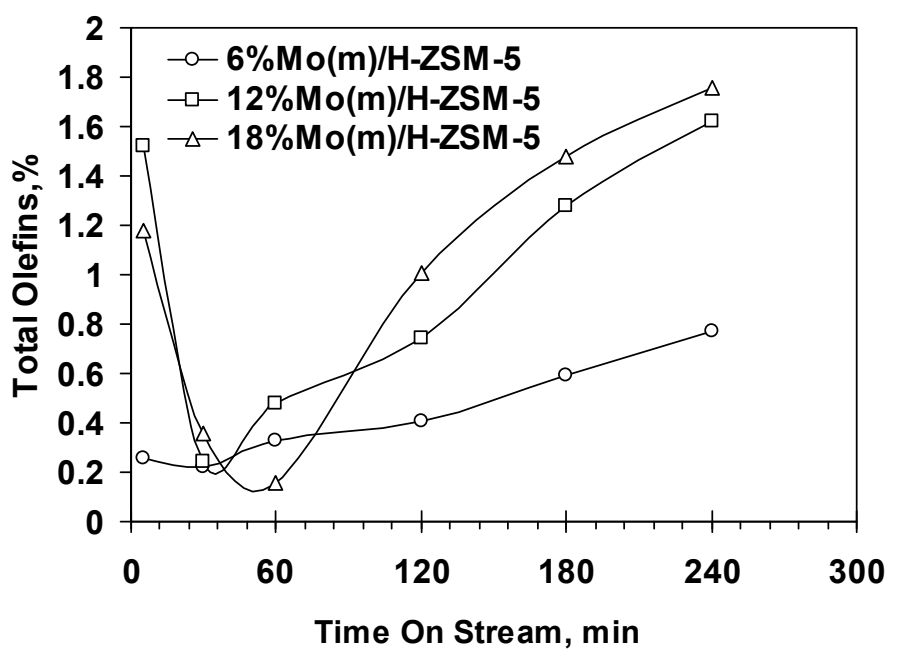

Fig. 10. Total olefins as a function of time on stream using mechanical Mo supported on H-ZSM-5 catalysts with different Mo loadings. 